MOBILIDADE DE FLUMIOXAZIN EM ARGISSOLO DA AMAZÔNIAMERIDIONAL

\title{
MOBILITY OF FLUMIOXAZIN IN ARGISOL AT SOUTHERN AMAZON
}

\author{
YAMASHITA,Oscar Mitsuo ${ }^{1 *}$; CARVALHO, Ricardo Vicentin ${ }^{2}$; CARVALHO, Marco Antônio \\ Camillo; ${ }^{1}$ TIEPPO, Rafael Cesar ${ }^{3}$; DALLACORT, Rivanildo ${ }^{3}$ \\ 1,2 Universidadedo Estado de Mato Grosso, Faculdade de Ciências Biológicas e Agrárias, Departamento de \\ Agronomia, Av.Perimetral Rogério Silva 4390, CEP 78580-000, Alta Floresta - MT, Brasil \\ (fone: +55 6635218203; fax: +55 6635211464) \\ ${ }^{3}$ Universidade do Estado de Mato Grosso, Departamento de Agronomia, MT-358, Jardim Aeroporto, CEP \\ 78300-000, Tangará da Serra - MT, Brasil \\ (fone: +55 653311 4900; fax: +55 6533114913 ) \\ ${ }^{*}$ Autor correspondente \\ e-mail:yama@unemat.br
}

Received 29 January 2018; received in revised form 12 April 2018; accepted 12 April 2018

\section{RESUMO}

O objetivo do presente trabalho foi determinar a mobilidade do flumioxazin em Argissolo, em função de dois índices pluviométricos, bem como passíveis influências das propriedades químicas e físicas, na ação do herbicida. Foram utilizados 32 tubos de PVC $(10 \mathrm{~cm}$ de diâmetro por $50 \mathrm{~cm}$ de altura). Estes recipientes foram preenchidos por completo com o Argissolocoletado na camada arável de uma área onde no histórico não constava a aplicação de herbicidas. Umedecido o solo, foi realizada a aplicação do flumioxazin $(50 \mathrm{~g}$ i.a. em 200 L/ha), nos tratamentos. Na sequência, foram simuladas chuvas de $10 \mathrm{~mm}$ ao dia, até atingir os níveis desejados de pluviosidade (40 e $80 \mathrm{~mm}$ ), para assim serem desmontados os tubos e semeadas 5 sementes de sorgo (Sorghum bicolor) em cada profundidade $(2,5 ; 5 ; 10 ; 15$ e $30 \mathrm{~cm}$ ), no perfil dos tubos. Estas foram mantidas por 15 dias em condições de campo para assim realizar a avaliação inicial. Foram realizadas as avaliações de altura, massa seca e fitointoxicação, para analisar possíveis alterações que pudesse ser caracterizadas como efeitos do herbicida. Nas condições experimentais, o flumioxazin foi pouco móvel, permanecendo na camada superficial $(2,5 \mathrm{~cm})$.

Palavras-chave: lixiviação, herbicida, contaminação.

\section{ABSTRACT}

The objective of the present work was to determine the mobility of flumioxazin in Argisol, as a function of two pluviometric indices, as well as possible influences of the chemical and physical properties, on the action of the herbicide. 32 PVC tubes were used $(10 \mathrm{~cm}$ in diameter by $50 \mathrm{~cm}$ in height). These containers were completely filled with the Argisol collected in the arable layer of an area where there was no herbicide application. Once the flumioxazin ( $50 \mathrm{~g}$ i.a. in $200 \mathrm{~L} / \mathrm{ha}$ ) was applied, the treatments were applied. Then, rainfall of $10 \mathrm{~mm}$ per day was simulated to reach the desired levels of rainfall $(40$ and $80 \mathrm{~mm})$, so that the tubes were dismantled and 5 sorghum seeds (Sorghum bicolor) were seeded each depth $(2.5 ; 5 ; 10 ; 15$ and $30 \mathrm{~cm}$ ) in the profile of the tubes. These were maintained for 15 days under field conditions to carry out the initial evaluation. Height, dry matter, and phytointoxication were evaluated to analyze possible changes that could be characterized as herbicide effects. Under experimental conditions, flumioxazin was sparingly mobile, remaining in the superficial layer $(2.5 \mathrm{~cm})$.

Keywords: lixiviation, herbicide, contamination. 


\section{INTRODUÇÃO}

O uso de herbicidas tem aumentado progressivamente ao longo dos últimos anos, correspondendo a $52 \%$ dos agroquímicos consumidos (Ferreira e Vegro, 2015). O aumento na síntese de novos herbicidas pelas indústrias tem levado pesquisadores a uma busca constante de respostas que ajudem a compreender 0 comportamento desses compostos no ambiente.

Tais produtos são aplicados com o objetivo de reduzir as populações de plantas daninhas e consequentemente aumentar a produtividade, além de obter produtos de qualidade. Entretanto, com o aumento do uso desses produtos, aumentaram também as preocupações com a contaminação do solo e da água, bem como com seus efeitos sobre os seres humanos e animais.

A contaminação ambiental causada pelo uso crescente de agroquímicos, em especial os herbicidas, tem gerado preocupações quanto ao lançamento inadequado desses compostos no ambiente (Assis et al., 2011). No Brasil, houve um aumento significativo no consumo de agroquímicos, principalmente dos herbicidas, em razão da expansão da fronteira agrícola e do aumento de terras onde é praticado o plantio direto (Tutidae Fogaça, 2018).

Como os sistemas de produção de grãos são predominantemente dependentes da aplicação de agroquímicos dos mais variados tipos, a possibilidade de lixiviação de moléculas tóxicas, e a consequente contaminação de rios e lagos deve ser considerada pelos agricultores e órgãos de gestão e fiscalização ambiental (Mancuso et al., 2011). Isto se torna um problema no momento em que há a introdução de água no sistema; seja proveniente da chuva ou do próprio sistema de irrigação da propriedade. Esta água, entrando em contato com as plantas e com o solo, dissolve algumas destas substâncias, levando-as, através de um movimento de infiltração, através dos poros do solo, até finalmente atingir a zona saturada do mesmo, afetando a qualidade das reservas subsuperficiais de água (Racke et al., 1997).

Por outro lado, a lixiviação é fator determinante para o sucesso ou fracasso da aplicação de herbicidas, pois é fundamental para a incorporação superficial da maioria dos herbicidas, permitindo que estes possam atingir as sementes ou plantas em germinação. A lixiviação será maior em solos de textura arenosa que em solos siltosos ou argilosos (Nicholls, 1988).

No solo, o herbicida pode sofrer adsorção, lixiviação e/ou degradação por processos físicos, químicos e biológicos, além de ser absorvido pelas plantas daninhas e/ou cultivadas (Resende et al., 1995). Para os herbicidas aplicados em pré-emergência, é desejável que ocorra pequena lixiviação, o que aumenta a eficiência dos produtos. Se por um lado a lixiviação aumenta a eficiência movendoos da superfície do solo para o local onde estão localizadas as sementes das plantas daninhas, por outro lado, quando há mobilidade excessiva, pode promover o contato do herbicida com as sementes da cultura, provocando-lhes injúrias ou fitointoxicação (Gelmini, 1988).

O conhecimento desses fatores é de fundamental importância para a previsão do comportamento de um herbicida nas diferentes classes de solo, para a seleção de dosagens adequadas e para evitar efeitos prejudiciais dos herbicidas sobre 0 ambiente $e$ as culturas subsequentes (Teixeira et al., 2017).

O flumioxazin (7-fluoro-6-[(3,4,5,6tetrahidro)ftalimida]-4-(2-propinil)-

1,4benzoxazino-3-(2H)-one), pertence ao grupo químico das ftalimidas, é um herbicida seletivo, não-sistêmico, recomendado para aplicação em pré e pós-emergência, destinado ao controle de plantas daninhas da cultura da soja e algodão, em solos de diferentes texturas (Rodrigues e Almeida, 2005); também, pode ser utilizado em associação com glyphosate no manejo da cobertura vegetal antes da semeadura da cultura (Rodrigues et al., 2000). Por poder ser utilizado em pré-emergência, é fundamental que se conheça sua atividade no solo. O conhecimento dos processos de sorção e lixiviação dos herbicidas no solo permite a recomendação de doses diferenciadas por tipo de solo e, consequentemente, controle mais eficiente das plantas daninhas (Velini, 1992).

Assim, o presente trabalho teve como objetivo avaliar a mobilidade do herbicida flumioxazin em Argissolo da Amazônia Meridional.

\section{MATERIAL E MÉTODOS}

O presente trabalho foi instalado e 
conduzido em casa telada, em área pertencente ao Laboratório de Tecnologia de Sementes e Matologia (LaSeM), do curso de Agronomia, da Universidade do Estado de Mato Grosso UNEMAT, Campus Universitário de Alta Floresta.

Foi avaliado o efeito da aplicação do herbicida flumioxazin, com posterior simulação de chuvas, sobre o desenvolvimento inicial de sorgo.

Como substrato, foram utilizadas amostras de Argissolocoletadas na Vicinal Favaro - 3 $3^{\text {a }}$ Sul, localizado no próprio município. Esse solofoi coletado em área de mata virgem, cujo histórico não constava nenhuma aplicação anterior de herbicidas.

Após a coleta, omaterial foi colocado para secar à sombra por um período de $48 \mathrm{~h}$, quando então foi peneirado e então submetido à análise química e granulométrica. As características químicas do solo, no perfil de $0-0,20 \mathrm{~m}$, após análise foram: $\mathrm{pH}\left(\mathrm{H}_{2} \mathrm{O}\right)$ de $5,3, \mathrm{P}$ e $\mathrm{K}$ de 2,0 e $70,0 \mathrm{mg} / \mathrm{dm}^{3}$ e teores de $\mathrm{Ca}, \mathrm{Mg}, \mathrm{Al}$ e $\mathrm{H}$ de 1,25; 0,$88 ; 0,19 ; 3,39 \mathrm{cmol}_{\mathrm{c}} / \mathrm{dm}^{3}$ e M.O. de $26,00 \mathrm{~g} / \mathrm{kg}$.

Como recipientes, foram utilizados tubos de PVC de $10 \mathrm{~cm}$ de diâmetro por $50 \mathrm{~cm}$ de comprimento. Estes tubos foram cortados longitudinalmente e fixados com fita adesiva, reconstituindo o original. As bases dos tubos foram fechadas com uma tela tipo mosquiteiro e, em seguida, estes foram parcialmente enterrados em areia e fixados em um suporte de madeira. Desta maneira, foram montados os tratamentos.

Após a montagem dos conjuntos de tubos preenchidos com os solos, foi realizada a aplicação do herbicidaflumioxazin ( $50 \mathrm{~g}$ i.a/ha) na área exposta dos solos contidos nos tubos de PVC, com o pulverizador de $\mathrm{CO}_{2}$ mantido à pressão constante de $400 \mathrm{kPa}$, munido de ponta de pulverização de jato plano Teejet 110.02, com gasto de calda de $200 \mathrm{~L} / \mathrm{ha}$.

Após a aplicação, esperou-se 24 horas, e então, foram simuladas chuvas diárias de 10 $\mathrm{mm}$, sendo que, a medida que se atingiu o índice pluviométrico desejado (40 ou $80 \mathrm{~mm}$ ), eram desmontados cinco tubos de cada tratamento, separando-se as partes e deitando-as. No solo contido em cada metade de tubo, foram semeadas cinco sementes de sorgo (Sorghum bicolor) a 2,5;5,0;10,0;15,0 e $30,0 \mathrm{~cm}$ da superfície na qual foi aplicado o herbicida. O ensaio de desenvolvimento inicial das plantas de sorgo foi conduzido por 15 dias.
O delineamento experimental, para cada tipo de solo, foi inteiramente casualizado, em esquema fatorial $2 \times 2 \times 5 \mathrm{com}$ tratamentos constituídos de herbicida (com ou sem), chuva (40 ou $80 \mathrm{~mm}$ ) e profundidades $(2,5 ; 5 ; 10 ; 15 \mathrm{e}$ $30 \mathrm{~cm})$, com 4 repetições.

Aos 15 dias após a semeadura foram realizadas avaliações das seguintes variáveis:

Altura de Planta: Com o auxílio de uma régua graduada, mediu-se da base da planta até o ápice da última folha lançada;

Peso da Massa Seca: as plantas foram cortadas e colocadas para secar em estufa com circulação forçada de ar $\left(70^{\circ} \mathrm{C}\right.$ por 96 horas) e pesadas em uma balança de precisão $(0,01 \mathrm{~g})$, para obtenção da biomassa seca.

Fitointoxicação: foram realizadas avaliações visuais de fitointoxicação nas plantas, com atribuição de notas que variam de 1 (sem fitointoxicação) a 9 (morte total da planta) (Tabela 1).

Tabela 1.Escala de avaliação visual de fitotoxicidade de herbicida sobre plantas, proposta pela Associação Lationoamericana de Malezas - ALAM, 1974.

\begin{tabular}{cl}
\hline Índice & Descrição do nível de controle \\
\hline 1 & Ausência de sintomas \\
2 & Sintomas muito leves \\
3 & Sintoma Leve \\
4 & Sintoma moderado \\
5 & Sintoma duvidoso \\
6 & Prejuízo leve na colheita \\
7 & Prejuízo forte na colheita \\
8 & Prejuízo muito forte na colheita \\
9 & Prejuízo total na colheita \\
\hline
\end{tabular}

Os dados obtidos foram submetidos à análise de variância pelo teste $F$ e as médias comparadas pelo teste de Tukey ao nível de 5\% e $1 \%$ de probabilidade.

\section{RESULTADOS E DISCUSSÃO:}

De acordo com os resultados obtidos, houve significância dos fatores isolados e da interação entre eles para a altura de planta. Já para a massa seca, observou-se a significância dos fatores isolados herbicida e chuva, e para a interação herbicida*chuva; porém, o fator profundidade e a interação entre herbicida e 
profundidade não foram significativos. $\mathrm{Na}$ avaliação de fitointoxicação, observou-se resultado significativo para herbicida e profundidade isoladamente, e para a interação herbicida* profundidade, mas a variável chuva e a interação herbicida*chuva, não foi significativo pelo teste de $\mathrm{F}$ (Tabela 2 ).

\section{Massa Seca}

Quanto à variável massa seca, houve diferença significativa entre os tratamentos, com exceção da profundidade e sua interação com herbicida. Dos resultados obtidos no experimento, observou-se diferença na quantidade de massa seca das plantas de sorgo, com e sem a aplicação do flumioxazin, dentro das precipitações simuladas, como pode ser observado na Tabela 3. Houve redução significativa no crescimento das plantas quando realizada a aplicação do herbicida em chuva de $80 \mathrm{~mm}$. Entretanto com $40 \mathrm{~mm}$ de chuva, não se observou diferença entre os volumes de massa seca produzida nos tratamentos com e sem herbicidas.

Tabela 3.Massa seca (g) de plantas de sorgo cultivado em Argissolo contaminado com herbicida flumioxazinsob condições de chuva simulada.

\begin{tabular}{ccc}
\hline \multirow{2}{*}{ Herbicida } & \multicolumn{2}{c}{ Chuva $(\mathbf{m m})$} \\
\cline { 2 - 3 } & $\mathbf{4 0}$ & $\mathbf{8 0}$ \\
\hline Com & $31,93 \mathrm{Aa}$ & $32,73 \mathrm{Ab}$ \\
Sem & $34,06 \mathrm{Ba}$ & $48,64 \mathrm{Aa}$ \\
\hline
\end{tabular}

Médias seguidas de mesma letra maiúscula nas linhas e minúscula nas colunas, dentro de cada tratamento herbicida, não diferem entre si pelo teste de Tukey a $5 \%$ de probabilidade.

Quando o sorgo foi cultivado em solo sem herbicida, este produziu maior volume de massa seca em chuva simulada de $80 \mathrm{~mm}$. Estes resultados demonstram que há resposta na produção de massa seca quando há maior fornecimento de água para as plantas, concordam com resultados obtidos por Rossi et al.(2005) com sulfentrazone.

Esses resultados demonstram que a ocorreu a lixiviação do herbicida e esta variou em função da quantidade de água presente no solo. Oliveira et al.(1999) também relataram lixiviação de flumioxazin até a $10,00 \mathrm{~cm}$ de profundidade em Latossolo Vermelho-amarelo, com chuvas simuladas de 45 e $90 \mathrm{~mm}$. Entretanto, diferem das informações relatadas por Deuberet al. (2009), em que o flumioxazin lixiviou apenas 2,75 $\mathrm{cm}$ em Latossolo Vermelho-eutroférrico e 2,20 $\mathrm{cm}$ em Latossolo Vermelho-amarelo distrófico, em simulação de $50 \mathrm{~mm}$ de chuvas. Possivelmente essas diferenças ocorreram devido á composição das argilas e da matéria orgânica presente nas diferentes classes de solo.

\section{Altura de Plantas}

Quanto à altura das plantas de sorgo, os resultadosdemonstraram resultado significativo ao nível de $5 \%$ de probabilidade, para todos os tratamentos, tanto isolados como em suas interações (Tabela 2).

Diferentemente de quando não houve a aplicação do flumioxazin, onde foram encontrados valores que demonstram a ausência do efeito do herbicida no crescimento das plântulas (Tabela 4), pode-se perceber um redução na altura quando o solo foi tratado com o herbicida.

Tabela 4.Altura de plantas de sorgo $(\mathrm{cm})$ cultivado emArgissolo contaminado com herbicida flumioxazinsob condições de chuva simulada.

\begin{tabular}{ccc}
\hline \multirow{2}{*}{ Herbicida } & \multicolumn{2}{c}{ Chuva $(\mathbf{m m})$} \\
\cline { 2 - 3 } & $\mathbf{4 0}$ & $\mathbf{8 0}$ \\
\hline Com & $18,19 \mathrm{Aa}$ & $18,21 \mathrm{Ab}$ \\
Sem & $18,79 \mathrm{Ba}$ & $21,62 \mathrm{Aa}$
\end{tabular}

Médias seguidas de mesma letra maiúscula nas linhas e minúscula nas colunas, dentro de cada tratamento herbicida, não diferem entre si pelo teste de Tukey a $5 \%$ de probabilidade.

A presença do herbicida no solo provocou reduzido elongamento das plantas apenas em chuvas simuladas de $80 \mathrm{~mm}$. Esta quantidade de água fornecida pode ter permitido uma lixiviação das partículas de flumioxazin, reduzindo-se assim sua disponibilidade e, consequentemente interferindo menos no crescimento das plantas de sorgo.

Comparando-se os resultados encontrados com as testemunhas (sem aplicação do herbicida), fica evidente 0 efeito do flumioxazin (Tabela 5), sendo observada redução significativa da altura de planta aos $2,5 \mathrm{~cm}$ deprofundidade. Segundo Rossi et al. (2005), que observaram resultados semelhantes, isto ocorre devido a uma maior disponibilidade do herbicida na superfície do solo. 
Tabela 5.Altura de plantas de sorgo $(\mathrm{cm})$ cultivado em Argissolo contaminado com herbicida flumioxazin em diferentes profundidades da coluna de PVC.

\begin{tabular}{ccc}
\hline \multirow{2}{*}{$\begin{array}{c}\text { Profundidade } \\
\text { (cm) }\end{array}$} & \multicolumn{2}{c}{ Herbicida } \\
\cline { 2 - 3 } & Com & Sem \\
\hline $\mathbf{2 , 5}$ & $16,54 \mathrm{Bb}$ & $20,33 \mathrm{Aab}$ \\
$\mathbf{5 , 0}$ & $18,31 \mathrm{Bab}$ & $20,60 \mathrm{Aab}$ \\
$\mathbf{1 0 , 0}$ & $19,18 \mathrm{Ba}$ & $21,30 \mathrm{Aa}$ \\
$\mathbf{1 5 , 0}$ & $18,16 \mathrm{Aab}$ & $19,31 \mathrm{Ab}$ \\
$\mathbf{3 0 , 0}$ & $18,80 \mathrm{Aa}$ & $19,49 \mathrm{Aab}$ \\
\hline
\end{tabular}

Médias seguidas de mesma letra maiúscula nas linhas e minúscula nas colunas, dentro de cada tratamento herbicida, não diferem entre si pelo teste de Tukey a $5 \%$ de probabilidade.

O efeito do herbicida ao longo do perfil do solo, para esta variável, é nítido, causando redução significativa no comprimento das plantas até $10 \mathrm{~cm}$ de profundidade. A partir daí, não há mais diferença entre os tratamentos, demonstrando que a esta profundidade, os resíduos do flumioxazin não mais são suficientes para provocar efeitos negativos na altura das plantas de sorgo.

\section{Fitointoxicação}

Observando os resultados visuais de fitotoxicidade do flumioxazin nas plântulas de sorgo, verifica-se uma tendência de acúmulo do herbicida nos $2,5 \mathrm{~cm}$ iniciais do solo, apresentando fortes sinais de intoxicação (Tabela 6). Na profundidade de $5,0 \mathrm{~cm}$, ainda foi observada fitointoxicação elevada. Após essa profundidade é possível perceber que a percolação do herbicida foi pequena.

Tabela 6. Fitointoxicação de plantas de sorgo cultivado em Argissolo contaminado com herbicida flumioxazin em diferentes profundidades da coluna de PVC.

\begin{tabular}{ccc}
\hline $\begin{array}{c}\text { Profundidade } \\
(\mathbf{c m})\end{array}$ & \multicolumn{2}{c}{ Herbicida } \\
\cline { 2 - 3 } & Com & Sem \\
\hline $\mathbf{2 , 5}$ & $4,98 \mathrm{Bc}$ & $1,12 \mathrm{Aa}$ \\
$\mathbf{5 , 0}$ & $3,00 \mathrm{Bb}$ & $1,33 \mathrm{Aa}$ \\
$\mathbf{1 0 , 0}$ & $1,87 \mathrm{Aa}$ & $1,41 \mathrm{Aa}$ \\
$\mathbf{1 5 , 0}$ & $2,06 \mathrm{Aa}$ & $1,60 \mathrm{Aa}$ \\
$\mathbf{3 0 , 0}$ & $1,84 \mathrm{Aa}$ & $1,40 \mathrm{Aa}$ \\
\hline
\end{tabular}

Médias seguidas de mesma letra maiúscula nas linhas e minúscula nas colunas, dentro de cada tratamento herbicida, não diferem entre si pelo teste de Tukey a $5 \%$ de probabilidade.

Estes resultados assemelham-se aos relatados por Rossi et al. (2005), que verificaram fortes sintomas de intoxicação para as plantas de sorgo colocadas para germinar a $2,5 \mathrm{~cm}$, e notas muito baixas para as plantas cultivadas além dessa profundidade, utilizando 0 herbicida sulfentrazone. Estes concluíram que houve uma tendência de acúmulo do herbicida nos $2,5 \mathrm{~cm}$ iniciais da superfície do solo, com baixa percolação até os $7,5 \mathrm{~cm}$, mesmo com os índices crescentes de precipitação.

Deuberet al. (2009) também observaram reduzida mobilidade do herbicida, observando-se fitointoxicação em pepino na simulação de 50 $\mathrm{mm}$ a apenas $1,50 \mathrm{~cm}$ de profundidade. A baixa lixiviação do herbicida, independentemente da umidade, tendo em vista sua baixa solubilidade em água tem sido relatada por outros estudos, indicando que a recomendação de aplicação deve ser direcionada de acordo com a capacidade adsortiva de cada solo (Oliveira et al., 1998; Lima et al., 1999).

\section{CONCLUSÕES:}

Nas condições do experimento conclui-se que ocorre maior concentração do flumioxazin nos 2,5 cm iniciais de Argissolo.

Com chuvas simuladas de $80 \mathrm{~mm}$ as plantas não sofrem o efeito do herbicida, devido á lixiviação deste.

Até a profundidade de $10 \mathrm{~cm}$, em que ocorre efeito do flumioxazin, há uma paralisação do crescimento das plantas, sendo mais explícitos nas simulações de $80 \mathrm{~mm}$ de chuva.

\section{REFERÊNCIAS:}

1. ALAM. AsociaciónLatinoamericana de Malezas. Recomendacionessobre unificación de los sistemas deevaluación em ensayos de control de malezas. ALAM, 1974, 1, 35.

2. Assis, E.C., D'Antonino, L., Queiroz, M.E.L.R., Barbosa, L.C. Leachingofpicloram in ultisolunder diferente rainfall volumes. Planta Daninha, 2011, 29, 1129.

3. Deuber, R.,Pastre, W.,Giusto, A.B. Lixiviação de flazasulfuron e flumioxazin em dois diferentes latossolos. RBrasHerb, 2009, 8, 27.

4. Ferreira, R.P.T., Vegro, C.L.R. Defensivos Agrícolas: em 2014, faturamento do segmento foi 0 destaque. Análises e 
Indicadores do Agronegócio, 2015, 10, 6.

5. Gelmini, G.A. Herbicidas: indicações básicas. 2th ed., Fundação Cargill: São Paulo, 1988.

6. Lima, R.O., Oliveira, M.F., Silva, A.A., Magalhães, J.V.Comportamento do herbicida flumioxazinem solo com diferentes doses de calcário. R. Ceres, 1999, 46, 607.

7. Mancuso, M.A.C., Negrisoli, E., Perim, L. Efeito residual de herbicidas no solo ("Carryover"). R BrasHerb, 2011, 10, 151.

8. Marques JR., J., Alves, P.L.C., Salgado, T.P., Rossi, C.V.S. Mobilidade do sulfentrazone no perfil de classes de solos, UNESP: Jaboticabal, 2005.

9. Nicholls, P.H. Factors influencing entry of pesticides into soil water. PestSci., 1988, 22, 123.

10. Oliveira, M.F., Silva, A.A., Ferreira, F.A., Ruiz, H.A. Lixiviação de flumioxazin e metribuzin em dois solos em condições de laboratório. Planta Daninha, 1999, 17, 207.

11. Oliveira, M.F.,Silva, A.A.,Neves, J.C.L. Influência do tamanho do agregado e do nível de umidade do solo na atividade do flumioxazin. R. Ceres, 1998, 45, 81.

12. Racke, K.D. Pesticide fate in tropical soils. PureAppl. Chem.,1997, 69, 1349.

13. Rodrigues, B.N., Almeida, F.S. Guia de herbicidas. 5th ed., Edição dos Autores: Londrina, 2005.

14. Rodrigues, B.N., Lima, J.,lada, I.F.U. Retenção pela palhada de herbicidas aplicados em pré-emergência na cultura do milho, em plantio direto. $\mathrm{R}$ BrasHerb, 2000, 1, 67.

15. Rossi, C.V.S., Alves, P.L.C.A., Marques J.R.J. Mobilidade do sulfentrazone em latossolo vermelho e em chernossolo. Planta Daninha, 2005, 23, 701.

16. Teixeira, M.F.F., Andrade, L.C.L., Biesdorf, E.M., Biesdorf, E.M., Souza, W.M., Paixão, G.P., Freitas, N.M. Leachingsulfentrazone in North soils of Minas Gerais cultivated with sugar cane. R BrasHerb, 2017, 16, 246.

17. Tutida, D., Fogaça, R. HowStuff Works Como funciona a contaminação dos solos. Disponível em: $<$ http://ambiente.hsw.uol.com.br/contamina cao-dos-solos2.htm> Acessado em Janeiro2018.

18. Velini, E.D. Comportamento de herbicidas no solo. Resumos do Simpósio Nacional sobre Manejo de Plantas Daninhas em Hortaliças, Botucatu, Brasil, 1992. 
Tabela 2. Quadrado médio e coeficiente de variação dos valores de massa seca, altura de planta e fitointoxicação de plantas de sorgo cultivadas em Argissolo, contaminado com flumioxazin. Alta Floresta - MT, 2008.

\begin{tabular}{lcccc}
\hline Causas da variação & G.L. & Massa seca & Altura de planta & Fitointoxicação \\
\hline Herbicida & 1 & $0,001626^{\star *}$ & $80,367020^{\star *}$ & $38,212301^{\star *}$ \\
Chuva & 1 & $0,001182^{\star *}$ & $40,669663^{\star *}$ & $0,374011^{\text {ns }}$ \\
Profundidade & 4 & $0,000089^{\text {ns }}$ & $7,790586^{* *}$ & $5,667329^{\star *}$ \\
Herbicida*Chuva & 1 & $0,000950^{\star *}$ & $39,573706^{\star *}$ & $0,559451^{\text {ns }}$ \\
Herbicida*Profundidade & 4 & $0,000179^{\text {ns }}$ & $5,743672^{\star *}$ & $8,797654^{\star *}$ \\
Resíduo & 68 & 0,000049 & 1,766777 & 0,295754 \\
\hline C.V. (\%) & & 19,00 & 6,92 & 26,33 \\
\hline
\end{tabular}

Nível de significância: ${ }^{*} p<0,05 ;{ }^{* *} p<0,01 ; n s=$ Não significativo 